\title{
Evidence that the stress hormone cortisol regulates biofilm formation differently among Flavobacterium columnare isolates
}

\author{
Annelies Maria Declercq ${ }^{1,2^{*}+}$ (D) Wenlong Cai ${ }^{3 \dagger}$, Eber Naranjo ${ }^{4}$, Wilawan Thongda ${ }^{5}$, Venessa Eeckhaut ${ }^{1}$, \\ Eva Bauwens ${ }^{1}$, Covadonga Arias ${ }^{3}$, Leonardo De La Fuente ${ }^{4}$, Benjamin H. Beck ${ }^{6}$, Miles D. Lange ${ }^{7}$, Eric Peatman ${ }^{5}$, \\ Freddy Haesebrouck', Johan Aerts ${ }^{2,8 \neq}$ and Annemie Decostere ${ }^{1 \neq}$
}

\begin{abstract}
The impact of cortisol on Flavobacterium columnare biofilm formation was explored. Firstly, the dynamics of biofilm formation by one highly (HV) and one low virulent (LV) F. columnare isolate with and without the stress hormone cortisol under microfluidic flow conditions was characterized. This to confirm that F. columnare cells could form biofilm under cortisol supplementation, and to compare the temporal and structural differences between different treatment groups. One trial revealed that in both isolates cell aggregates resembling biofilms occurred within 7-h post-inoculation. Consequently, cell clusters were sloughed away, followed by a rebuilding of bacterial cell aggregates, suggestive for a high spreading capacity. While the HV isolate revealed cell aggregates formed upstream at all time-points, for the $\mathrm{LV}$ isolate this was only seen upon cortisol supplementation. Secondly, the transcriptional effect of genes ( $\mathrm{g} / \mathrm{dK}$, $\mathrm{g} / \mathrm{dL}$, gldM, gld N, sprA, sprE, sprT, and porV) belonging to the Type IX secretion system involved in gliding motility was investigated in planktonic and biofilm cells of a HV and LV isolate to which no, a low (LD) or high (HD) dose of cortisol was added. Significantly lower expression of gliding genes gldK, gldL, gldM and $g / d \mathrm{~N}$, and of protein secretion regulator porV was seen in the LV isolate planktonic cells supplemented with a HD-cortisol. The LV isolate biofilm cells treated with the HD-cortisol showed a significant upregulation of sprT, encoding mobile surface adhesion important in bacterial colonization. This is the first evidence for the co-regulatory effect of cortisol on biofilm formation and F. columnare gliding gene expression.
\end{abstract}

\section{Introduction}

Living organisms survive by maintaining an equilibrium, or homeostasis, that is continuously challenged by intrinsic or extrinsic disturbing stimuli [1]. The latter are called stressors, and are defined as stimuli that trigger a stress response [2]. Fish that endure stress react by initiating an endocrine stress response through the activation of the hypothalamic-pituitary-interrenal axis, which results in the release of glucocorticoids into the blood, in particular cortisol in teleost fish [3, 4]. Cortisol exerts effects at both

\footnotetext{
*Correspondence: andclerc.declercq@ugent.be

${ }^{\dagger}$ Annelies Maria Declercq and Wenlong Cai shared first co-authorship

‡Johan Aerts and Annemie Decostere shared last co-authorship

${ }^{1}$ Department of Pathology, Bacteriology and Poultry Diseases, Faculty

of Veterinary Medicine, Ghent University, Ghent 9000, Belgium

Full list of author information is available at the end of the article
}

the blood and tissue level [4], and is further excreted via the mucus, urine, and faeces [5]. Stress is not necessarily detrimental to fish [3]. A distinction should be made between stressors that stimulate the animal ("eustress"), and those that may result in a chronic, pathological state ("distress") [4]. Indeed, if a stressor persists over time, or when too intensive, the stress response may lose its adaptive value and become dysfunctional $[2,4]$.

For the majority of bacterial fish pathogens, chronic stress is considered a key factor in disease outbreaks as is the case for Flavobacterium columnare ( $F$. columnare), the causative agent of columnaris disease $[6,7]$. This disease can give rise to multiple clinical signs, such as skin lesions, mouth rot, and gill lesions [7] and causes huge financial losses in carp, catfish and trout aquaculture [6, 8-10]. A consistent finding 
throughout the challenges performed by Declercq et al. $[11,12]$ was the marked individual variation in susceptibility to columnaris disease, especially for the fish exposed to the low virulent isolate. Clinically healthy fish were co-present with moribund animals displaying severe gill pathology following inoculation with a low virulent $F$. columnare isolate. Currently, a thorough explanation for these results is being debated. Individual coping styles of fish have been attributed to varying cortisol levels in fish following an acute stress stimulus [13, 14]. In the aforementioned immersion challenges to reproduce columnaris disease, netting the fish and placing them in the inoculation bath for 90 min were shown to be stress stimuli. The challenge procedure itself may have resulted in fish displaying varying plasma and mucus cortisol levels engendering different degrees of susceptibility towards the different $F$. columnare isolates with which the fish were exposed. To validate this line of reasoning, one may propose there is a direct effect of cortisol on the $F$. columnare bacterial cells. Indeed, a recent study from our lab revealed a dose-dependent impact of cortisol on the colony morphology of $F$. columnare [15]. The higher the cortisol concentration in the bacterial cultures, the less rhizoid the resulting colonies were [15]. Gliding is a well-described trait for $F$. columnare cells $[6,16$, 17] and is reflected in the rhizoid shape of colonies, a feature positively linked to virulence [18]. The type IX secretion system (T9SS) is required for gliding motility as it is involved in the secretion of cell surface proteins of the gliding apparatus [19-22]. Genetic analyses suggest that GldK, GldL, GldM, GldN, SprA, SprE, SprT, and PorV are T9SS components [21, 22]. This system is needed for the secretion of SprB and RemA, mobile surface adhesins involved in gliding and movement over surfaces. Cells with mutations in the genes encoding these adhesins were affected in gliding [23] and failed to attach to glass [21].

The formation of biofilms on gill filaments is an important step in establishing gill pathology in columnaris disease as observed during in vivo trials [12]. Biofilm formation is a multistage process that is initiated through different stimuli with free-living or planktonic bacterial cells gliding over a surface prior to attachment [24-26]. The cells lose their motility and cluster together [27] and are then referred to as sessile or biofilm cells. Bearing in mind the above cited effects of cortisol on the rhizoid shape of the bacterial colonies and their gliding motility, one might expect that the presence of cortisol may impact the capacity to form biofilms. Likewise, differential expression of gliding motility genes may be presumed in biofilm-forming cells versus their free-swimming counterparts following incubation in the presence and/or absence of cortisol.

In this framework, the objective of the present study was to evaluate whether cortisol has an impact on $F$. columnare biofilm formation among a low (LV) and highly virulent (HV) carp (Cyprinus carpio) isolate, with special interest in the effect on the LV isolate. Biofilm formation was evaluated under conditions of flow by using microfluidic chambers as previously described [27, 28]. Although the complex operational control, this set-up provided important advantages such as real-time analysis and ability to perform perfusion culture by injecting bacteria into an environment under continuous flow. As loss of $F$. columnare gliding is important to initiate biofilm formation [27] the impact of cortisol on the expression of genes $(g l d \mathrm{~K}, g l d \mathrm{~L}, g l d \mathrm{M}$ and $g l d \mathrm{~N}, s p r \mathrm{~A}, s p r \mathrm{E}$, spr $\mathrm{T}$, and por $\mathrm{V}$ ) involved in motility, adhesion and protein secretion of Flavobacteriaceae was evaluated. This was done in biofilm-forming versus planktonic cells of a low and highly virulent $F$. columnare isolate to which no, a low or a high dose of cortisol was added. This study is the first to investigate whether cortisol directly steers the gliding capacity in $F$. columnare on a genetic level and therefore impacts biofilm formation, hence providing new insights into $F$. columnare virulence mechanisms.

\section{Materials and methods \\ F. columnare culture conditions}

Flavobacterium columnare isolates 0901393 and CDI-A recovered from carp were used in this study. Their virulence profiles were previously determined $[11,12]$. Isolates 0901393 and CDI-A have been shown to be highly virulent (HV) and low virulent (LV), respectively, in laboratory challenges. Both isolates are genomovar I, as determined by the Aquatic Microbiology Laboratory of Auburn University (Alabama, USA) using 16S-restriction fragment length polymorphism protocol [29].

The isolates were grown in triplicate for $36 \mathrm{~h}$ at $28{ }^{\circ} \mathrm{C}$ on modified Shieh agar plates. For each of the three plates per isolate, five random colonies (all colonies grown showed homogenous sizes and rhizoid shapes) per plate were transferred into $15 \mathrm{~mL}$ Falcon tubes filled with $4 \mathrm{~mL}$ of modified Shieh broth, which were shaken overnight at $28^{\circ} \mathrm{C}$ and $150 \mathrm{rpm}$. Of the cultivated broths, $1 \mathrm{~mL}$ was added to $150 \mathrm{~mL}$ Erlenmeyer flasks filled with $99 \mathrm{~mL}$ of modified Shieh broth (1/100 dilution). Cortisol (hydrocortisone-water soluble, Sigma Aldrich, Overijse, Belgium) was dissolved in ultrapure water, filtered through a $0.2 \mu \mathrm{m}$ filter (Millipore, Bedford, USA) and diluted to obtain a final concentration in the broth culture of $500 \mu \mathrm{g} / \mathrm{L}$ (high dose; HD) and $50 \mu \mathrm{g} / \mathrm{L}$ (low dose; LD) accounting for $1.378 \mu \mathrm{M}$ and $0.138 \mu \mathrm{M}$ cortisol, respectively. For each isolate, the HD and LD of cortisol 
was added and a non-treated control with only sterile ultrapure water were tested in triplicate (biological replicates). Flasks were incubated at $28^{\circ} \mathrm{C}$ for $24 \mathrm{~h}$ at $150 \mathrm{rpm}$. One $\mathrm{mL}$ of each tube was collected to measure optical densities (OD). The $\mathrm{OD}_{600}$ of the $24 \mathrm{~h}$ cultured broths was $0.45 \pm 0.05$.

For the microfluidic chamber experiments, one $\mathrm{mL}$ of one HD cortisol and control cultivated broth cultures of the $\mathrm{HV}$ and LV isolates was transferred into a $1 \mathrm{~mL}$ syringe and coupled to an automated syringe pump and injected into a microfluidic chamber as described below.

For the gene expression study, both planktonic and biofilm cells were harvested from each cultivated HD or LD cortisol, and control broth cultures (hence triplicates) of the HV and LV isolates. For the planktonic cells, $99 \mathrm{~mL}$ of each cultivated broth was divided equally over three $50 \mathrm{~mL}$ Falcon tubes and centrifuged $\left(4{ }^{\circ} \mathrm{C}, 4750 \mathrm{~g}\right)$ for $20 \mathrm{~min}$. Biofilm cells were scraped from the edge of the Erlenmeyer flask with a cell scraper (Greiner Bio One, Vilvoorde, Belgium). Pellets from planktonic and biofilm cells were transferred to a $1.5 \mathrm{~mL}$ Eppendorf tube, after which $500 \mu \mathrm{L}$ RNA later (Ambion ${ }^{\circledR}$ Thermo Fisher Scientific) was added. Samples were stored at $4{ }^{\circ} \mathrm{C}$ for $24 \mathrm{~h}$, after which they were frozen at $-20^{\circ} \mathrm{C}$ until analysis.

\section{Microfluidic chambers}

Biofilm formation under flow conditions was evaluated by using microfluidic chambers $[27,28]$ which were composed of two parallel microchannels $(80 \mu \mathrm{m}$ wide by $3.7 \mathrm{~cm}$ long by $50 \mu \mathrm{m}$ deep). The chamber consisted of a molded polydimethylsiloxane body, attached to a cover slip and a supporting glass microscope slide. Each channel had two inlets to allow the separate entry of media and bacteria, and an outlet to allow media and bacteria to flow out via the other end. The channels were completely filled with fluid and the flows in the media inlets were started simultaneously to avoid air bubbles in the tubing during the experiment. Modified Shieh medium was collected in $10 \mathrm{~mL}$ syringes which were coupled via an automated syringe pump to the media inlet. The flow of the modified Shieh medium inside the chamber was kept constant $(10 \mu \mathrm{L} / \mathrm{min})$ for the duration of each experiment. In the first experiment, the HV and LV isolates growth was compared in parallel at room temperature $\left(24^{\circ} \mathrm{C}\right)$ for $24 \mathrm{~h}$ to verify whether biofilm was formed and if so, what qualitative differences in biofilm formation between both isolates could be observed. Cell suspensions were introduced into each channel via the bacterial inlet at $1 \mu \mathrm{L} / \mathrm{min}$ for $1 \mathrm{~h}$, after which bacterial inflow was stopped. In a second trial, for each isolate, parallel comparisons were made between the control and HD of cortisol cultivated in broth. The flow rate of the bacteria was kept constant at $1 \mu \mathrm{L} / \mathrm{min}$ for the entire duration of the experiment $(12 \mathrm{~h})$ to prevent the chambers from clogging. Each microfluidic experiment was performed in singlefold merely to confirm that $F$. columnare cells could indeed form biofilm under cortisol supplementation, and to compare the temporal and structural differences between the different treatment groups. Microfluidic chambers were mounted onto a Nikon Eclipse Ti inverted microscope (Nikon, Melville, NY, USA) and observed at $40 \times$ with phase-contrast optics to monitor cell aggregation and biofilm formation for the duration of each experiment. Images were captured every $30 \mathrm{~s}$ by using a Nikon DS-Q1 digital camera (Nikon) controlled by NISElements software (Nikon).

\section{Differential gene expression studies between biofilm and planktonic cells $R N A$ extraction and $R T-q P C R$}

The bacterial cells were centrifuged (5000 $g, 20 \mathrm{~min}$ ) and the RNA later was removed from the samples, after which $1 \mathrm{~mL}$ TRIzol $^{\mathrm{TM}}$ (Invitrogen Thermo Fisher Scientific) was added. Subsequently, the samples were homogenized by pipetting up and down. Samples containing twelve $2.3 \mathrm{~mm}$ silica beads were placed in the Tissue Lyser (Qiagen, Antwerp, Belgium) three times for $45 \mathrm{~s}$ at $20 \mathrm{~Hz}$, with one min between each cycle during which the samples were preserved on ice. Samples were then centrifuged for $5 \mathrm{~min}$ at $4{ }^{\circ} \mathrm{C}$ and $12000 \mathrm{~g}$ and the supernatant was transferred to a new Eppendorf tube. After five min incubation at room temperature (RT), $0.2 \mathrm{~mL}$ chloroform (Sigma Aldrich, Overijse, Belgium) was added per $1 \mathrm{~mL}$ TRIzol ${ }^{\mathrm{TM}}$. After another incubation period of three min at RT, the samples were centrifuged for $30 \mathrm{~min}$ at $4{ }^{\circ} \mathrm{C}$ and $12000 \mathrm{~g}$. The colorless, upper aqueous phase was transferred to a new Eppendorf tube and one volume of $100 \%$ ethanol (VWR, Oud-Heverlee, Belgium) was added. The content of the tube was then loaded onto an RNeasy spin column (RNeasy Mini Kit, Qiagen), according to manufacturer's protocol. The flowthrough was discarded. Thirty $\mu \mathrm{L}$ RNase-free water was added directly to the spin membrane and centrifuged for one min at $8000 \mathrm{~g}$ to elute the RNA. The flow-through contained the total RNA and residual genomic DNA was removed with DNA-free ${ }^{\text {TM }}\left(\right.$ Ambion $^{\circledR}$ Thermo Fisher Scientific) according to the manufacturer's instructions. RNA concentration was measured with a NanoDrop ${ }^{\circledR}$ ND-1000 Spectrophotometer.

High-quality RNA samples were used to initiate first strand cDNA synthesis. One $\mu \mathrm{g}$ of DNAse-treated RNA was used as template in $20 \mu \mathrm{L}$ cDNA synthesis reactions applying iScript ${ }^{\mathrm{TM}} \mathrm{cDNA}$ Synthesis Kit (Bio-Rad, Temse, Belgium). cDNA synthesis reactions were incubated for five min at $25^{\circ} \mathrm{C}, 20 \mathrm{~min}$ at $46^{\circ} \mathrm{C}$, and $1 \mathrm{~min}$ at $95^{\circ} \mathrm{C}$. Each cDNA sample was then diluted 1/10. Afterwards, 
$10 \mu \mathrm{L}$ of each cDNA sample was pooled to set up a twofold dilution standard curve. Each cDNA sample was run in triplicate using a CFX384 ${ }^{\mathrm{TM}}$ RT-PCR System or a

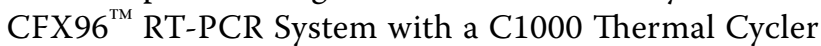
(Bio-Rad, Hercules, CA, USA). The reaction mixture of $12 \mu \mathrm{L}$ consisted of $6 \mu \mathrm{L}$ of $\mathrm{iQ}^{\mathrm{TM}} \mathrm{SYBR}^{\circledR}$ Green Supermix (Bio-Rad), $3.95 \mu \mathrm{L}$ of high pressure liquid chromatography water (Merck Millipore, Overijse, Belgium), $0.025 \mu \mathrm{L}$ of each primer $(0.05 \mu \mathrm{M})$, and $2 \mu \mathrm{L}$ cDNA. The amplification conditions were as follows: $95{ }^{\circ} \mathrm{C}$ for $3 \mathrm{~min}$, followed by 40 cycles of $95^{\circ} \mathrm{C}$ for $10 \mathrm{~s}$ and $60^{\circ} \mathrm{C}$ as melting temperature for $30 \mathrm{~s}$. Intra-run variability was ascertained by comparing the obtained $\mathrm{Cq}$-values for the standard twofold dilution series of cDNA within one RT-PCR run, whereas inter-run variability was evaluated by comparing those values between three RT-PCR runs (see further). The amplification efficiency and $\mathrm{R}^{2}$ were calculated using the Bio-Rad CFX Manager v1.6 software (Bio-Rad) (Table 1).

\section{qPCR primer design and validation}

Primers for amplifying the reference genes were chosen based on previous work by Penttinen et al. [30], and those from the genes of interest based on Penttinen et al. [31] or were designed for use in this study. IDT PrimerQuest Tool [32] was used to design own primer pairs for target genes. The sequences of the primers used in this study are listed in Table 1 . The preliminary expression stability testing was first performed with four reference gene candidates (16S rRNA; gap; glyA; rplQ) using a mixture of all test samples $(N=36)$ that included samples from planktonic and biofilm cells collected from $F$. columnare cultured in modified Shieh broth to which no, a LD, or a HD of cortisol was added. The data was checked for normality and the expression stabilities were determined via qBase and geNorm and calculated per $F$. columnare isolate. According to these methods, gap and glyA possessed the best stabilities and were chosen to be used as reference genes in the expression analysis of the dataset of each $F$. columnare isolate. Furthermore, DNAse treated

Table 1 Primer sequences and amplicon details used in RT-qPCR assay for Flavobacterium columnare

\begin{tabular}{|c|c|c|c|c|c|}
\hline Primer name & Sequence $\left(5^{\prime}-3^{\prime}\right)$ & $\begin{array}{l}\text { Amplicon length } \\
\text { (bp) }\end{array}$ & Efficiency (\%) & $\mathrm{R}^{2}(\%)$ & References \\
\hline \multicolumn{6}{|c|}{ Primers for target genes (gld-genes are involved in motility, spr-genes in adhesion and porV in virulence) } \\
\hline FC_gldK_fwd & GCCAAATAGCACCCTCTATCA & 102 & 103.0 & 98.9 & This study \\
\hline FC_gldK_rev & AACAGAAGCCGAATGGGAATA & & & & \\
\hline FC_gldL_fwd & GCTTCTGTACCTAAACCAGCA & 94 & 99.9 & 99.5 & This study \\
\hline FC_gldL_rev & TTGGTGCGGCAGTAGTAATC & & & & \\
\hline FC_gldM_fwd & ACTACCACATCACCTCTTTGTG & 93 & 102.4 & 99.2 & This study \\
\hline FC_gldM_rev & TCCAGGGCAACCAACAATAG & & & & \\
\hline FC_gldN_fwd & GCAAGCGCTATGCTTATTGCTGGT & 131 & 97.8 & 99.0 & {$[31]$} \\
\hline FC_gldN_rev & GCAGTTGGTTGTCCCCCTGCT & & & & \\
\hline FC_sprA_fwd & AGGCGATGGTATTTCGTTAGG & 122 & 101.9 & 99.5 & This study \\
\hline FC_spra_rev & GTACGCGTCCTGCTTGATAA & & & & \\
\hline FC_sprE_fwd & AGCCGTGCAGAAGATAAAGC & 151 & 92.4 & 99.0 & {$[31]$} \\
\hline FC_sprE_rev & ACGCTTCTAATGCGGGTACAA & & & & \\
\hline FC_sprT_fwd & AACCAGGACTGCATTACGGA & 144 & 91.1 & 99.2 & {$[31]$} \\
\hline FC_sprT_rev & GCTTGATGTTACCTGTGCGTT & & & & \\
\hline FC_porV_fwd & GTGCCAACTCCTAAAACAGCC & 152 & 102.7 & 99.3 & {$[31]$} \\
\hline FC_porV_rev & AAACCTCCTGGAGCATCACC & & & & \\
\hline \multicolumn{6}{|c|}{ Primers for reference genes } \\
\hline FC_16S_fwd & ACGATCAAACGGCCATTG & 119 & 105.0 & 99.4 & {$[30]$} \\
\hline FC_16S_rev & AGTAACCTGCCTTCGCAATC & & & & \\
\hline FC_gap1_fwd & ACCATCCCAAACAGGAGCCGC & 98 & 103.3 & 99.3 & {$[30]$} \\
\hline FC_gap1_rev & CGTCTGCTGTAGGTACGCGCA & & & & \\
\hline FC_glyA_fwd & CCAAACCCTTGGGGCTATACAACCC & 98 & 103.2 & 99.6 & {$[30]$} \\
\hline FC_glyA_rev & AGAGGGCCTCCTTGATTACCTGGAA & & & & \\
\hline FC_rplQ_fwd & AGCTGCTAAAGTAGGTGACCGTCC & 75 & 96.7 & 99.1 & {$[30]$} \\
\hline FC_rplQ_rev & GCGTTATCTCCTAAACGGTTCCCCA & & & & \\
\hline
\end{tabular}


RNA samples were pooled and included in the RT-qPCR assays to assure no hybridization of cDNA to the RNA occurred. A no template control was also included.

\section{Statistics}

All parameters were statistically modeled using Graphpad Prism 7 with cortisol concentration $(0,50$, or $500 \mu \mathrm{g} / \mathrm{L}$ ), and cell type (planktonic, or biofilm) as fixed effects. The modelled outcomes were the qPCR-data of the RNA-expression of each of the target genes ( $g l d \mathrm{~K}$, $g l d \mathrm{~L}, g l d \mathrm{M}$ and $g l d \mathrm{~N}, s p r \mathrm{~A}, s p r \mathrm{E}, s p r \mathrm{~T}$, and $p o r \mathrm{~V}$ ) and the two final reference genes (glyA and gap). Expression levels were normalized to the expression of reference genes. The data were analyzed using Wilcoxon matched-pairs signed rank test to compare treatments with the control data within each cell type. Differences were considered to be significant when $p$-values were lower than 0.05 .

\section{Results}

\section{Microfluidic chambers}

The cells of both the HV and LV isolates clustered rapidly within $4 \mathrm{~h}$ post-inoculation (pi), at the bacterial inlet side of the channel. Cell aggregates resembling biofilm filled the entire channel within $7 \mathrm{~h}$ pi (see Additional file 1), starting at the bacterial inlet and building up to the middle to eventually reach the opposite side of the channel. Consequently, cell clusters were sloughed away, whereby the channels were cleared, immediately followed by a rebuild of bacterial cell aggregation. At the end of the observation period, the bacterial cells of the HV isolate also formed cell aggregates upstream of the bacterial inlet. For the LV isolate, bacterial cell cluster formation was only seen downstream in the channel (Figure 1).

Different patterns of bacterial cell aggregation were observed upon parallel comparison of the HV isolate with no and a HD of cortisol. For the latter, more organized cell aggregates lining up at one-third of the microfluidic chamber were noted, whereas this was not the case for the non-supplemented bacterial cells (Figure 2).

Parallel comparisons of the LV isolate with no and a HD of cortisol revealed that the latter formed aggregates that filled the channels from the side of bacterial inlet up to the middle of the chamber by the end of the experiment (12 h pi). Moreover, cell clusters were formed upstream from the bacterial inlet (Figure 3), and these phenomena were not observed for the non-supplemented LV isolate.

\section{Differential gene expression between biofilm and planktonic cells QPCR primer design and validation}

The expression stability of each isolate was measured using the qbase and geNorm methods. Hereby, gap and gly $A$ showed the best stability and were subsequently

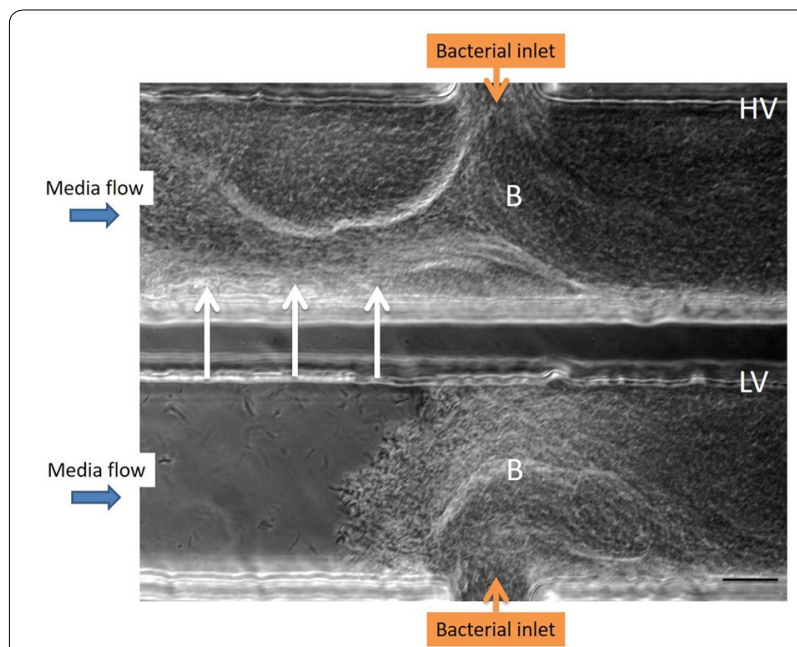

Figure 1 Biofilm formation of $F$. columnare isolates in a microfluidic chamber. Biofilm formation (B) of the highly virulent (HV, upper channel) and low virulent (LV, lower channel) F. columnare isolate are compared in parallel at $24 \mathrm{~h}$ pi. Bacterial cell suspensions were introduced into each channel via the bacterial inlet at $1 \mu \mathrm{L} /$ min for $1 \mathrm{~h}$, after which bacterial inflow was stopped. For the HV isolate, bacterial cell clusters completely fill the channel and are even encountered upstream (arrowheads), while the latter is not observed for the LV isolate. This microfluidic experiment was performed in singlefold merely to grasp whether both F. columnare isolates could form biofilm formation in the microfluidic chambers. Scale bar $20 \mu \mathrm{m}$.

selected as reference genes used for normalization of the gene expression data. M (mean stability)- and CV (coefficient of variation)-values were averaged resulting 0.88 and 0.30 for the HV isolate and 0.74 and 0.26 for the LV isolate, respectively. All were found to be under the maximum allowed values of 1 and 0.5 for $\mathrm{M}$ and $\mathrm{CV}$, respectively.

\section{Genetic analyses of genes involved in the T9SS of F. columnare grown with various cortisol levels}

The results of the mean relative gene expression \pm SEM are presented in Table 2, Figure 4, and Additional file 2.

For all gld-genes in both the HV and LV isolates a significantly higher expression was found in the planktonic cells compared to their biofilm counterparts in the control broth, except for $g l d \mathrm{~K}$ and $g l d \mathrm{~N}$ in the $\mathrm{HV}$ isolate. When comparing planktonic and biofilm cells incubated in the presence of a HD cortisol (Table 2), this could not be observed.

A significant downregulation was noted for sprA ( $\mathrm{HV}+\mathrm{LV}$ isolate), and sprE ( $\mathrm{HV}$ isolate) in the untreated planktonic cells in comparison with the untreated biofilm cells. For the planktonic cells supplemented with a HD cortisol, a significant downregulation of sprA (HV isolate), and upregulation of $\operatorname{spr} T$ (HV isolate) was observed (Table 2). 


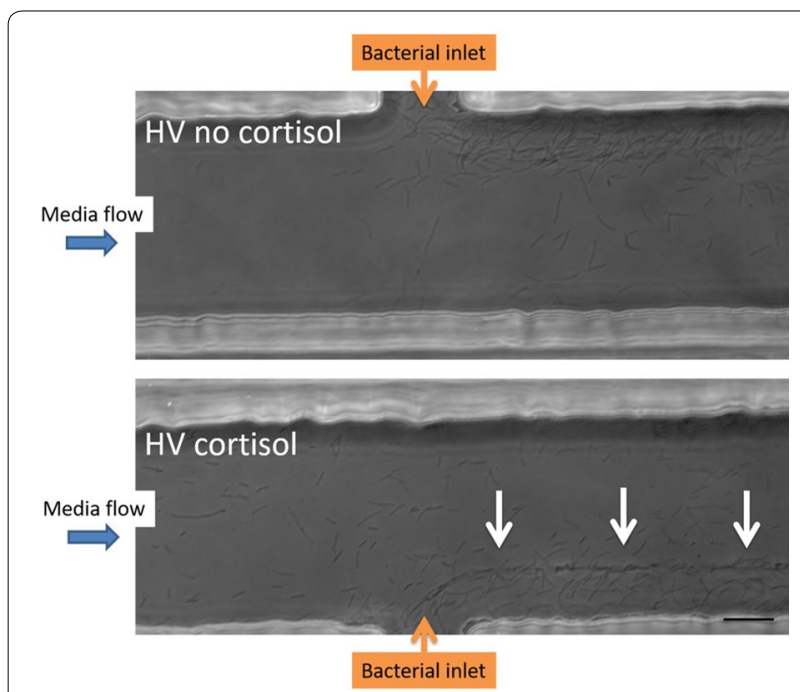

Figure 2 Biofilm formation of HV F. columnare isolate stimulated with cortisol. Biofilm formation of the highly virulent (HV) isolate cultivated without (upper channel) and with (lower channel) a high dose of cortisol is compared in parallel at $4 \mathrm{~h}$ pi. The flow rate of the bacteria was kept constant at $1 \mu \mathrm{L} / \mathrm{min}$ for the entire duration of the experiment $(12 \mathrm{~h})$ to prevent the chambers from clogging. The cortisol supplemented bacterial cells display a more organized cell clustering lining-up at one-third of the microfluidic chamber (white arrows). As the bacterial inflow remained constant during the whole trial to prevent the chamber from clogging, the thickness of biofilm formation was smaller compared to the one formed in the first experiment (Figure 1) in which the complete channel was filled. This microfluidic experiment was performed in singlefold merely to grasp whether the HV F. columnare isolate supplemented with and without cortisol could for biofilm formation in the microfluidic chambers. Scale bar $20 \mu \mathrm{m}$.

In planktonic cells of the LV isolate a HD cortisol resulted in a significant downregulation of $g l d \mathrm{~K}, g l d \mathrm{~L}$, $g l d \mathrm{M}, g l d \mathrm{~N}$ and $p o r \mathrm{~V}$ while a LD cortisol significantly downregulated $s p r \mathrm{E}, g l d \mathrm{~K}$, and $g l d \mathrm{~L}$ compared to the planktonic control cells to which no cortisol was added. A significant inverse relationship for $g l d \mathrm{~K}$ and $g l d \mathrm{~L}$ was observed between cortisol concentration and gene expression level, with a HD cortisol resulting in more downregulation. In regard to the biofilm cells of the LV isolate incubated in the presence of a HD cortisol, a significant upregulation of $s p r \mathrm{~T}$ was observed.

With regard to the HV isolate, no other significant differences in gene expression levels were encountered.

\section{Discussion}

Biofilm formation on the fish's skin and gills is a wellknown feature in fish succumbing to columnaris disease [11, 12]. A more profound knowledge of the biofilm formation and how it interplays with the environment and the host is pivotal to better understand and subsequently mitigate and treat this disease. The pertinent literature describes a plethora of techniques to study biofilm biomass, viability, structure, composition and physiology [25]. For F. columnare, biofilm development is visualized applying glass slides, histology, confocal laser scanning microscopy, and scanning and transmission electron microscopy [11, 12, 27]. Cai et al. [27] were the first to use microfluidic flow chambers to assess differences between F. columnare isolates in the ability to attach to glass surfaces and form biofilm under flow conditions. This technique has unprecedented potential due to the generated flow and offers a direct and non-destructive observation of developing biofilms providing continuous flow conditions as could be encountered in the aquatic environment [27]. The advantage is that with this system, the process of biofilm formation can be studied spatially and temporarily in conditions that mimic the natural habitats of these bacteria. In the present study, biofilm formation of a HV and LV F. columnare isolate was compared in parallel in these microfluidic chambers. Both isolates formed cell aggregates resembling biofilm that filled the complete channel within $7 \mathrm{~h}$ pi. This is in contrast to the findings of Cai et al. [27], where the HV isolate was able to develop microcolonies completely colonizing the channel whereas the LV isolate remained confined to the sides. We speculate that the different phenomena of the biofilm development were due to strain or physicochemical variations in the test. Strains of different genomovars have exhibited great genetic heterogeneity $[33,34]$ and the response to physiochemical factors has proven to be significantly different among different isolates [27]. In this study, only in the channel filled with the HV isolate, bacterial fragments were shown to detach and disperse several times during the $24 \mathrm{~h}$ observation period. This phenomenon occurred only once in the channel of the LV isolate. The building up of cell aggregates, detaching, and rebuilding again, is indicative for the spreading capacity of HV F. columnare cells. The tendency of individual microcolonies containing biofilm cells to break off when their tensile strength is exceeded, is reported to have the greatest impact on the outcome of (persisting) bacterial infections [35] and permits bacterial cells to escape the confines of the biofilm and colonize new areas [36]. Though caution is needed when extrapolating results of the microfluidic chambers as the experiments were not repeated in time, these new findings might explain results encountered in former in vivo trials where the $\mathrm{HV}$ isolate induced gill lesions throughout the entire gill, while for the majority of carp challenged with the LV isolate colonization halted at the filament middle section $[11,12]$.

Important criteria to incorporate in the development of a model biofilm system are the media flow rate and shear forces [33]. Shear stress suppresses the development of a biofilm matrix but provides more opportunities 


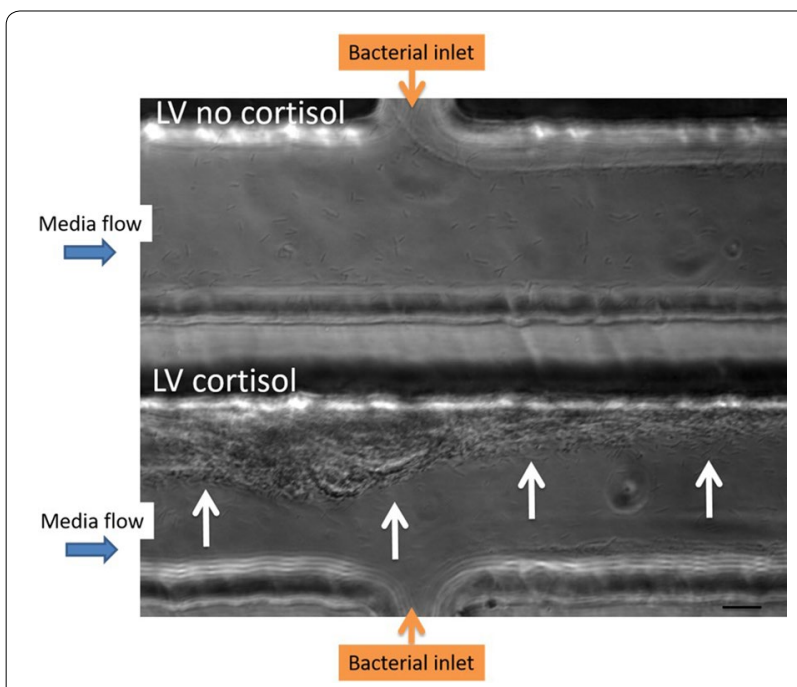

Figure 3 Biofilm formation of LV F. columnare isolate stimulated with cortisol. Biofilm formation of the low virulent (LV) isolate cultivated without (upper channel) and with (lower channel) a high dose (HD) of cortisol is compared in parallel at $12 \mathrm{~h}$ pi. The flow rate of the bacteria was kept constant at $1 \mu \mathrm{L} / \mathrm{min}$ for the entire duration of the experiment ( $12 \mathrm{~h}$ ) to prevent the chambers from clogging. The bacterial cells of the LV isolate with HD of cortisol form aggregates filling the channel up to the middle and moreover biofilm formation upstream from the bacterial inlet (white arrows) is seen, whereas this was not the case for the non-supplemented LV isolate. In the latter, only downstream biofilm formation is seen. As the bacterial inflow remained constant during the whole trial to prevent the chamber from clogging, the thickness of biofilm formation was smaller compared to the one formed in the first experiment (Figure 1) in which the complete channel was filled. This microfluidic experiment was performed in singlefold merely to grasp whether the LV F. columnare isolate supplemented with and without cortisol could for biofilm formation in the microfluidic chambers. Scale bar $20 \mu \mathrm{m}$.

for new biofilm formation [37]. The latter would occur by improving motility [37], and providing more opportunities for bacterial cells to adhere and disperse [38]. A balance between the two opposing effects may be needed to provide optimal shear stress conditions for promoting biofilm growth [37]. In this study, a continuous high media flow was chosen according to previous studies $[27,39]$. The chamber created lower shear forces at the sides of the channels, with the maximum shear force at the middle of the channel [27]. Moreover, a high flow rate prevents the chambers from clogging over time, which has been mentioned as a limitation of microfluidic channels [25].

The cortisol doses added to the bacterial broths in the gene expression trials were 50 (LD) and $500 \mu \mathrm{g} / \mathrm{L}(\mathrm{HD})$, respectively. One may raise the question via what tissues bacterial cells come in contact with this stress hormone. The first matrix F. columnare encounters upon adhering to the gill tissue, is the mucus. As far as we know, studies measuring cortisol levels in mucus of fish are confined to those of Guardiola et al. [40]. The latter research group compared the cortisol levels retrieved in serum and skin mucus of gilthead seabream (Sparus aurata L.) and surrounding water after acute crowding of the fish. Two hours after onset of the acute stress, only plasma cortisol levels $(345.74 \pm 23.99 \mu \mathrm{g} / \mathrm{L})$ were significantly higher compared to unstressed control animals. At $24 \mathrm{~h}$ after exposure, plasma cortisol levels decreased and were no longer significantly different from those of the control animals, while skin mucus and water cortisol levels were significantly elevated compared to the controls with levels of $111.98 \pm 9.22$ and $29.02 \pm 4.61 \mu \mathrm{g} / \mathrm{L}$, respectively. However, one must take into account that the concentration level of excreted non-metabolized cortisol is just a minor fraction of the total glucocorticoids present in the water and on the mucus. Subsequently, one could argue whether these values were a sum of glucocorticoids instead of just cortisol as the antibody based enzymatic immunoassay is biased by cross-reactivity making in-depth analytical validation of utmost importance. As a consequence, extrapolation of these findings to gill mucus remains to be elucidated. Noteworthy is that, already at $4 \mathrm{~h}$ post-challenge with a $\mathrm{HV}$ isolate, gill filament destruction is evident resulting in $F$. columnare bacterial cells coming into direct contact with plasma, which hence may be a second manner whereby the bacterial cells may be exposed to cortisol. Plasma, the most used matrix for quantification of acute stress across vertebrate species, is known to show a variety of cortisol levels ranging from low (e.g. from circadian rhythmicity) to extremely high (e.g. from severe, uncontrollable, intense, unpredictable stressor). Based on this broad range of plasma cortisol values, the tested concentrations were selected. Hereby, HD $(500 \mu \mathrm{g} / \mathrm{L})$ was chosen to mimic plasma cortisol levels retrieved from carp blood following an acute stressor, as for example Bertotto et al. [41] found average values of $396.8 \pm 192.3 \mu \mathrm{g} / \mathrm{L}$ while unstressed animals revealing plasma cortisol levels of $80.7 \pm 42.6 \mu \mathrm{g} / \mathrm{L}(P<0.01)$. The HD cortisol hereby ensuring an initial glance on a "physiological" level of cortisol, while the LD cortisol representing plasma cortisol levels of unstressed control individuals.

As mentioned, to enable $F$. columnare cells to form microcolonies on glass slides, gliding capacity is lost [27]. At this point, they are referred to as sessile or biofilm cells. A significant downregulation of the gliding genes $g l d \mathrm{~K}, g l d \mathrm{~L}$, $g l d \mathrm{M}$ and $g l d \mathrm{~N}$ was seen in the planktonic cells upon incubating the LV isolate culture in the presence of cortisol. Moreover, $g l d \mathrm{~K}$ and $g l d \mathrm{~L}$ showed a significant inverse relationship between cortisol concentrations and gene expression levels, with higher cortisol doses resulting in less gene expression, suggesting a dose-response effect. In F. johnsoniae, gld $\mathrm{K}$, gld L, gld $\mathrm{M}$ 
Table 2 Mean relative gene expression results \pm SEM

\begin{tabular}{|c|c|c|c|c|c|c|c|c|c|}
\hline Gene & Isolate & $\mathrm{CT}$ & $\begin{array}{l}\text { Mean } \pm \text { SEM } \\
0\end{array}$ & $\begin{array}{l}\text { Mean } \pm \text { SEM } \\
50\end{array}$ & Mean \pm SEM500 & $\begin{array}{l}p \text {-value } \\
0 \text { vs } 50\end{array}$ & $\begin{array}{l}p \text {-value } \\
0 \text { vs } 500\end{array}$ & $\begin{array}{l}p \text {-value } \\
\mathrm{P}_{\mathrm{C}} \text { vs } \mathrm{B}_{\mathrm{C}}\end{array}$ & $\begin{array}{l}p \text {-value } \\
P_{500} \text { vs } B_{500}\end{array}$ \\
\hline \multirow[t]{4}{*}{ gldK } & LV & $\mathrm{P}$ & $7.2 \pm 1.3$ & $4.6 \pm 0.9$ & $2.8 \pm 0.5$ & $0.03^{*}$ & $0.004^{* *}$ & $0.004^{* *}$ & $0.04^{*}$ \\
\hline & & B & $4.3 \pm 0.5$ & $3.9 \pm 0.8$ & $3.3 \pm 0.6$ & NS & NS & & \\
\hline & $\mathrm{HV}$ & $\mathrm{P}$ & $12.3 \pm 1.9$ & $12.5 \pm 2.0$ & $8.2 \pm 2.2$ & NS & NS & NS & NS \\
\hline & & B & $9.1 \pm 2.3$ & $11.3 \pm 2.3$ & $9.9 \pm 1.0$ & NS & NS & & \\
\hline \multirow{4}{*}{$g / d L$} & LV & $\mathrm{P}$ & $58.5 \pm 6.5$ & $36.9 \pm 5.5$ & $24.9 \pm 2.0$ & $0.03^{*}$ & $0.004^{* *}$ & $0.004^{* *}$ & NS \\
\hline & & B & $33.3 \pm 3.5$ & $31.2 \pm 5.3$ & $27.6 \pm 3.3$ & NS & NS & & \\
\hline & $\mathrm{HV}$ & $P$ & $75.8 \pm 7.8$ & $94.8 \pm 10.7$ & $68.2 \pm 16.1$ & NS & NS & $0.03^{*}$ & NS \\
\hline & & B & $20.4 \pm 8.8$ & $56.7 \pm 10.0$ & $46.8 \pm 9.6$ & NS & NS & & \\
\hline \multirow[t]{4}{*}{ gldM } & LV & $P$ & $31.4 \pm 5.7$ & $21.0 \pm 4.0$ & $15.5 \pm 1.5$ & NS & $0.004^{* *}$ & $0.03^{*}$ & NS \\
\hline & & B & $25.9 \pm 6.5$ & $21.4 \pm 6.0$ & $15.0 \pm 1.0$ & NS & NS & & \\
\hline & $\mathrm{HV}$ & $P$ & $192.3 \pm 23.7$ & $283.2 \pm 68.0$ & $248.0 \pm 40.5$ & NS & NS & $0.047^{*}$ & NS \\
\hline & & B & $59.8 \pm 31.9$ & $204.6 \pm 37.6$ & $116.1 \pm 20.9$ & NS & NS & & \\
\hline \multirow[t]{4}{*}{$g / d N$} & LV & $P$ & $12.0 \pm 1.5$ & $8.8 \pm 1.2$ & $6.0 \pm 0.6$ & NS & $0.008^{* *}$ & $0.02^{*}$ & $0.008^{* *}$ \\
\hline & & B & $6.8 \pm 0.9$ & $5.7 \pm 0.9$ & $6.9 \pm 0.8$ & NS & NS & & \\
\hline & $\mathrm{HV}$ & $P$ & $502.2 \pm 66.9$ & $552.9 \pm 79.6$ & $407.2 \pm 89.6$ & NS & NS & NS & NS \\
\hline & & B & $268.8 \pm 131.3$ & $313.5 \pm 59.1$ & $258.2 \pm 59.0$ & NS & NS & & \\
\hline \multirow[t]{4}{*}{ sprA } & LV & P & $4.2 \pm 1.3$ & $3.9 \pm 0.9$ & $5.1 \pm 1.4$ & NS & NS & $0.004^{* *}$ & NS \\
\hline & & B & $17.7 \pm 6.1$ & $22.6 \pm 7.9$ & $18.0 \pm 6.5$ & NS & NS & & \\
\hline & $\mathrm{HV}$ & $P$ & $3.5 \pm 0.9$ & $3.4 \pm 0.3$ & $4.0 \pm 0.6$ & NS & NS & $0.03^{*}$ & $0.03^{*}$ \\
\hline & & B & $25.3 \pm 4.3$ & $23.3 \pm 5.9$ & $18.7 \pm 3.5$ & NS & NS & & \\
\hline \multirow[t]{4}{*}{ sprE } & LV & $P$ & $2.1 \pm 0.1$ & $1.8 \pm 0.2$ & $2.3 \pm 0.4$ & $0.008^{* *}$ & NS & NS & NS \\
\hline & & B & $3.8 \pm 0.7$ & $2.8 \pm 0.4$ & $4.2 \pm 0.9$ & NS & NS & & \\
\hline & $\mathrm{HV}$ & $P$ & $98.6 \pm 18.3$ & $96.0 \pm 13.4$ & $124.0 \pm 21.6$ & NS & NS & $0.03^{*}$ & NS \\
\hline & & B & $406.6 \pm 159.4$ & $149.3 \pm 18.4$ & $150.2 \pm 51.0$ & NS & NS & & \\
\hline \multirow[t]{4}{*}{ sprT } & LV & P & $2.6 \pm 0.4$ & $3.1 \pm 0.1$ & $3.4 \pm 0.6$ & NS & NS & NS & NS \\
\hline & & B & $3.2 \pm 0.5$ & $3.3 \pm 0.5$ & $5.0 \pm 0.6$ & NS & $0.04^{*}$ & & \\
\hline & $\mathrm{HV}$ & $P$ & $13.9 \pm 2.2$ & $13.2 \pm 1.4$ & $19.4 \pm 1.2$ & NS & NS & NS & $0.04^{*}$ \\
\hline & & B & $37.1 \pm 19.2$ & $11.3 \pm 2.2$ & $10.0 \pm 2.7$ & NS & NS & & \\
\hline \multirow[t]{4}{*}{ porv } & LV & $P$ & $6.6 \pm 0.7$ & $6.0 \pm 0.5$ & $4.2 \pm 0.4$ & NS & $0.008^{* *}$ & NS & $0.008^{* *}$ \\
\hline & & B & $5.8 \pm 0.7$ & $5.5 \pm 0.9$ & $6.1 \pm 0.6$ & NS & NS & & \\
\hline & $\mathrm{HV}$ & $\mathrm{P}$ & $70.6 \pm 12.7$ & $80.1 \pm 10.3$ & $94.6 \pm 17.9$ & NS & NS & NS & NS \\
\hline & & B & $607.2 \pm 364.5$ & $63.4 \pm 14.7$ & $47.5 \pm 15.0$ & NS & NS & & \\
\hline
\end{tabular}

These include planktonic (P) and biofilm (B) cells of the highly (HV) and low (LV) virulent $F$. columnare isolate to which a cortisol dose of 0 (control), 50 (LD) or $500 \mu \mathrm{gg} / \mathrm{L}$ (HD) was added.

0,50 or 500 : added cortisol concentration in $\mu \mathrm{g} / \mathrm{L} ; \mathrm{Mean}=$ mean relative gene expression level; $S E M$ : standard error of means; $\mathrm{P}_{C}$ vs $\mathrm{B}_{\mathrm{C}}$ : gene expression in the planktonic cells of the control group compared to the gene expression in the biofilm cells of the control group; $P_{500}$ vs $B_{500}$ : gene expression in the planktonic cells treated with $500 \mu \mathrm{g} / \mathrm{L}$ cortisol compared to the gene expression in the biofilm cells treated with $500 \mu \mathrm{g} / \mathrm{L}$ cortisol; significantly different $p$-values are marked in italics with one asterisk indicating $p$-values $<0.05$ and two asterisks $p$-values $<0.01 ; p$-values depicted are the exact $p$-values obtained after Wilcoxon matched-pairs signed rank test. NS: not significant.

and $g l d \mathrm{~N}$ form an operon [21] and the proteins encoded by these genes interact to form part of the F. johnsoniae T9SS. Cells with mutations in these genes, grow well as wild-type cells but are completely non-motile [23]. In $F$. columnare in particular, gene mutation in $g l d \mathrm{~N}$ results in bacteria that lack gliding motility [22]. Hence, one might expect that a downregulation of these genes will decrease motility, possibly urging the planktonic cells to adhere and form biofilms. The finding that the expression of the gld-genes was significantly lower in the biofilm cells compared to their planktonic counterparts, endorses the above stated hypothesis. This was also encountered in $F$. psychrophilum, in which motility-related genes (amongst which $g l d \mathrm{~J}, g l d \mathrm{~N}, g l d \mathrm{M}$, and $g l d \mathrm{~L}$ ) were significantly downregulated in the biofilm state [42]. This phenomenon was no longer encountered upon comparing planktonic and biofilm cells incubated in the presence of a HD cortisol. Li et al. [22] found that $\Delta g l d \mathrm{~N}$ mutants exhibited 

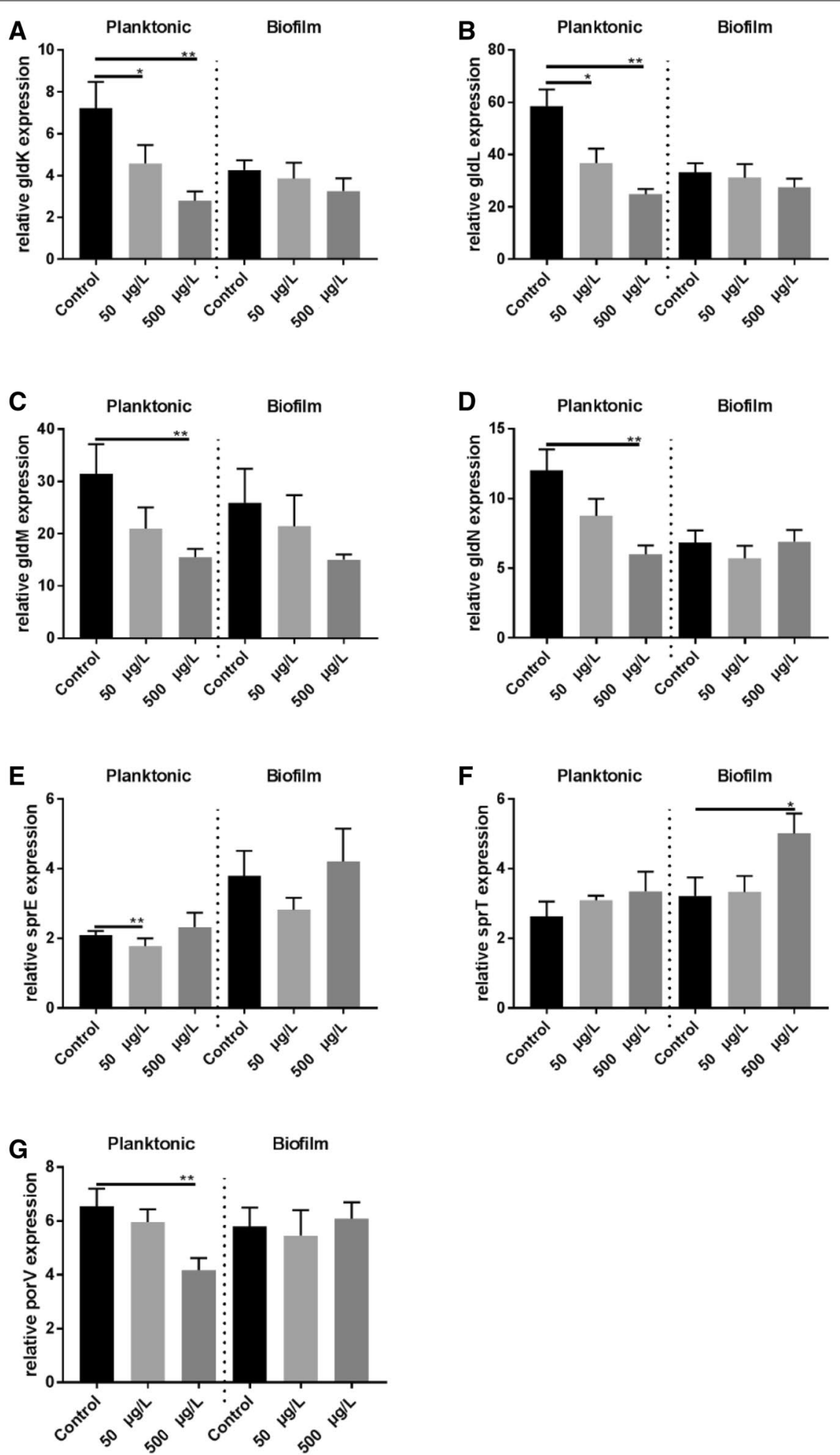

Figure 4 Mean relative gene expression results \pm SEM. Mean relative gene (gldK $(\mathbf{A})$, gldL $(\mathbf{B})$, gldM $(\mathbf{C})$, gldN (D)), (sprE) (E), sprT (F), and porV (G)) expression results \pm SEM in planktonic and biofilm cells of the low (LV) virulent $F$. columnare isolate following supplementation with a low (50 $\mu \mathrm{g} / \mathrm{L})$ or high $(500 \mathrm{\mu g} / \mathrm{L})$ cortisol dose. Only statistically significant differences are presented. The error bars indicate the standard error means and the asterisks indicate significantly different results compared to the non-supplemented controls. Significance levels are indicated on the graphs *, $0.01 \leq P<0.05 ; * *, 0.001 \leq P<0.01$. 
reduced virulence with complementation restoring virulence. Furthermore, in this study, a significant downregulation in porV was found in the planktonic cells of the $\mathrm{LV}$ isolate treated with the HD cortisol. For F. columnare, mutants in this gene exhibited reduced virulence, but retained gliding motility [22]. These findings might suggest that cortisol may also interfere with protein secretion and hence impact virulence. However, further research is imperative to refute or rectify this hypothesis.

Another interesting finding was the significant upregulation of sprT in the biofilm cells collected from the LV isolate treated with the HD cortisol. SprT belongs to T9SS [19, 21, 43, 44].

The results of this study support the initial research hypothesis that cortisol, as dominant stress-induced glucocorticoid in teleost fish, exerts a favorable effect on the initial colonization process in the course of disease in the LV F. columnare cells. In the latter, a switch from a planktonic to sessile state might be induced by a downregulation in gliding genes, and hence a loss of the gliding characteristic. Once biofilm cells of the LV isolate are formed, the high dose of cortisol might induce an upregulation in genes involved in adhesion and eventual biofilm maturation. The latter matches with the results obtained from the microfluidic chamber experiments in which the LV isolate grown in media supplemented with cortisol, resulted in cell aggregate formation found upstream from the bacterial inlet, referring to adhesion capacities in high shear-environments. This study is the first to demonstrate a direct triggering effect of cortisol on biofilm formation in a bacterial pathogen. This finding again accentuates the need for mitigating stress in aquaculture, thereby not only abolishing a possible impairment of the immune system, but also breaking through a potential direct stimulating effect on biofilm formation by cortisol and possibly other glucocorticoids as commonly encountered in the water.

\section{Additional files}

\footnotetext{
Additional file 1. Movie of a microfluidic chamber experiment. The upper chamber shows the highly virulent $F$. columnare cell aggregates resembling biofilm filling the entire channel within $7 \mathrm{~h} \mathrm{pi}$, starting at the bacterial inlet and building up to the middle of the channel to eventually reach the opposite side of the channel. The cell aggregates are thick, dense structures, representative of a dense biofilm. The lower chamber shows the build-up of cell aggregates of the low virulent $F$. columnare isolate.
}

Additional file 2. Mean relative gene expression results $\pm S E M$. Differential gene gldK (A), gldL (B), gldM (C), gldN (D), porV (E), sprA (F), sprE $(\mathrm{G}), \operatorname{spr} \mathrm{T}(\mathrm{H})$ expression in planktonic and biofilm cells of highly ( $\mathrm{HV}$, isolate 090) virulent $F$. columnare isolates following supplementation with a low $(50 \mu \mathrm{g} / \mathrm{L})$ or high $(500 \mu \mathrm{g} / \mathrm{L})$ cortisol dose. (I) represents the differential sprA expression of the low (LV, isolate CDI-A) virulent F. columnare isolate.
No statistically significant differences were found in the results presented in this graph. The error bars indicate the standard error means.

\section{Abbreviations}

F. columnare: Flavobacterium columnare; HV: highly virulent; LV: low virulent; HD: high dose; LD: low dose; pi: post-inoculation; M: mean stability; CV: coefficient of variation.

\section{Competing interests}

The authors declare that they have no competing interests.

\section{Authors' contributions}

AMD: overall experimental design and execution of all laboratory experiments, writing of the manuscript, interpretation of all data; WC: design and execution of gene expression experiments; EN: design and execution of microfluidic chamber experiments; WT: design of gene expression experiments; VE: design of gene expression experiments; EB: data processing of gene expression experiments and statistics; CA: design experimental set-ups; LDLF: design microfluidic chamber experiments; BHB; design experimental set-ups, writing manuscript; MDL: design experimental set-ups, writing manuscript; EP: design gene expression experiments; FH: design experimental set-ups; JA: experimental set-up cortisol trials; AD: overall design experimental set-ups and writing manuscript. All authors read and approved the final manuscript.

\section{Acknowledgements}

The authors wish to thank Helena Berlamont, Chana Callens, Sofie De Bruyckere, Marleen Foubert, Sarah Van Praet, and Nathalie Van Rysselberghe for their excellent technical input. The HV carp isolate was kindly provided by Dr. ir. Olga L.M. Haenen (Fish and Shellfish Diseases Laboratory, Central Veterinary Research Institute (CVI), Wageningen, the Netherlands). The Special Research Grant (Bijzonder Onderzoeksfonds, BOF, Grant Number BOF.PDO.2015.0020.01) of Ghent University, Belgium and the Fund for Scientific Research (FWO, Grant V423316N), Flanders, Belgium are gratefully acknowledged for financial support.

\section{Author details}

${ }^{1}$ Department of Pathology, Bacteriology and Poultry Diseases, Faculty of Veterinary Medicine, Ghent University, Ghent 9000, Belgium. ${ }^{2}$ Stress Physiology Research Group, Faculty of Pharmaceutical Sciences, Ghent University, Ostend 8400, Belgium. ${ }^{3}$ School of Fisheries, Aquaculture, and Aquatic Sciences, Aquatic Microbiology Laboratory, Auburn University, Auburn, AL 36849, USA. ${ }^{4}$ Department of Entomology and Plant Pathology, Auburn University, Auburn, AL 36849, USA. ${ }^{5}$ School of Fisheries, Aquaculture, and Aquatic Sciences, Aquatic Genetics and Genomics, Auburn University, Auburn, AL 36849, USA. ${ }^{6}$ United States Department of Agriculture, Agricultural Research Service, Aquatic Animal Health Research Unit, Auburn, AL 36849, USA. ${ }^{7}$ United States Department of Agriculture, Agricultural Research Service, Harry K. Dupree Stuttgart National Aquaculture Research Center, Stuttgart, AR 72160, USA.

${ }^{8}$ Stress Physiology Research Group, Animal Sciences Unit, Flanders Research Institute for Agriculture, Fisheries and Food, Ostend 8400, Belgium.

\section{Funding}

The research was funded by the Special Research Grant (Bijzonder Onderzoeksfonds, BOF, Grant Number BOF.PDO.2015.0020.01) of Ghent University, Belgium and the Fund for Scientific Research (FWO, Grant V423316N), Flanders, Belgium.

\section{Publisher's Note}

Springer Nature remains neutral with regard to jurisdictional claims in published maps and institutional affiliations.

Received: 18 December 2018 Accepted: 24 February 2019

Published online: 11 April 2019 


\section{References}

1. Chrousos GP, Gold PW (1992) The concepts of stress and stress system disorders. Overview of physical and behavioral homeostasis. JAMA 267:1244-1252

2. Novais A, Monteiro S, Roque S, Correia-Neves M, Sousa N (2017) How age, sex and genotype shape the stress response. Neurobiol Stress 6:44-56

3. Barton BA (2002) Stress in fishes: a diversity of responses with particular reference to changes in circulating corticosteroids. Integr Comp Biol 42:517-525

4. Wendelaar Bonga SE (1997) The stress response in fish. Physiol Rev 77:591-626

5. Scott AP, Ellis T (2007) Measurement of fish steroids in water-a review. Gen Comp Endocr 153:392-400

6. Bernardet JF, Bowman JP (2006) The genus Flavobacterium. In: Dworkin M, Falkow S (eds) The Prokaryotes: a handbook on the biology of bacteria. Proteobacteria: delta and epsilon subclasses. Deeply rooting bacteria, vol 7 Springer Science + Business Media, New York

7. Declercq AM, Boyen F, Van den Broeck W, Bossier P, Karsi A, Haesebrouck F, Decostere A (2013) Antimicrobial susceptibility pattern of Flavobacterium columnare isolates collected worldwide from 17 fish species. J Fish Dis 36:45-55

8. Pulkkinen K, Suomalainen L-R, Read AF, Ebert D, Rintamaki P, Valtonen ET (2010) Intensive fish farming and the evolution of pathogen virulence: the case of columnaris disease in Finland. Proc Biol Sci 277:593-600

9. Singh T (1997) Common culture practices for cyprinids in Asia. Southeast Asian J Trop Med Public Health 28(Suppl 1):73-76

10. Li N, Guo H, Jiao R, Zhang S, Liu Z, Yao W, Nie P (2011) Identification and pathogenicity of bacterial pathogens isolated in an outbreak on bacterial disease of Ctenopharyngodon idellus. Acta Hydrobiol Sin 35:980-987

11. Declercq AM, Chiers K, Haesebrouck F, Van den Broeck W, Dewulf J, Cornelissen M, Decostere A (2015) Gill infection model for columnaris disease in common carp and rainbow trout. J Aquat Anim Health 27:1-11

12. Declerca AM, Chiers K, Van den Broeck W, Dewulf J, Eeckhaut V, Cornelissen M, Bossier P, Haesebrouck F, Decostere A (2015) Interactions of highly and low virulent Flavobacterium columnare isolates with gill tissue in carp and rainbow trout Vet Res 46:25

13. Øverli $\varnothing$, Sørensen C, Pulman KGT, Pottinger TG, Korzan W, Summers CH, Nilsson GE (2007) Evolutionary background for stress coping styles: relationships between physiological, behavioral, and cognitive traits in non-mammalian vertebrates. Neurosci Biobehav Rev 31:396-412

14. Castanheira MF, Herrera M, Costas B, Conceição LEC, Martins CIM (2013) Can we predict personality in fish? Searching for consistency over time and across contexts. PLoS One 8:e62037

15. Declercq AM, Aerts J, Ampe B, Haesebrouck F, De Saeger S, Decostere A (2016) Cortisol directly impacts Flavobacterium columnare in vitro growth characteristics. Vet Res 47:84

16. Decostere A, Haesebrouck F, Devriese L (1997) Development of a medium for the selective isolation of Flavobacterium columnare from diseased fish. Clin Microbiol 35:322-324

17. Decostere A, Haesebrouck F, Devriese LA (1998) Characterization of four Flavobacterium columnare (Flexibacter columnaris) strains isolated from tropical fish. Vet Microbiol 62:35-45

18. Kunttu HMT, Jokinen EI, Valtonen ET, Sundberg LR (2011) Virulent and nonvirulent Flavobacterium columnare colony morphologies: characterization of chondroitin AC lyase activity and adhesion to polystyrene. J Appl Microbiol 111:1319-1326

19. Sato K, Naito M, Yukitake H, Hirakawa H, Shoji M, McBride MJ, Rhodes RG Nakayama K (2010) A protein secretion system linked to bacteroidetes gliding motility and pathogenesis. Proc Natl Acad Sci USA 107:276-281

20. Shrivastava A, Rhodes RG, Pochiraju S, Nakane D, McBride MJ (2012) Flavobacterium johnsoniae RemA is a mobile cell-surface lectin involved in gliding. J Bacteriol 194:3678-3688

21. Shrivastava A, Johnston JJ, van Baaren JM, McBride MJ (2013) Flavobacterium johnsoniae GldK, GldL, GldM, and SprA are required for secretion of the cell-surface gliding motility adhesins SprB and RemA. J Bacteriol 195:3201-3212

22. Li N, Zhu Y, LaFrentz BR, Evenhuis JP, Hunnicutt DW, Conrad RA, Barbier P, Gullstrand CW, Roets JE, Powers JL, Kulkarni SS, Erbes DH, García JC, Nie P,
McBride MJ (2017) The type IX secretion system is required for virulence of the fish pathogen Flavobacterium columnare. Appl Environ Microbiol 83:e01769-e01817

23. McBride MJ, Zhu Y (2013) Gliding motility and Por secretion system genes are widespread among members of the phylum bacteroidetes. J Bacteriol 195:270-278

24. Flemming HC, Wingender J (2010) The biofilm matrix. Nat Rev Microbio 8:623-633

25. Azeredo J, Azevedo NF, Briandet R, Cerca N, Coenye T, Costa AR, Desvaux M, Di Bonaventura G, Hébraud M, Jaglic Z, Kačániová M, Knøchel S, Lourenço A, Mergulhão F, Meyer RL, Nychas G, Simões M, Tresse O, Sternberg C (2017) Critical review on biofilm methods. Crit Rev Microbiol 43:313-351

26. Lange MD, Farmer BD, Declercq AM, Peatman E, Decostere A, Beck BH (2017) Sickeningly sweet: L-rhamnose stimulates Flavobacterium columnare biofilm formation and virulence. J Fish Dis 40:1613-1624

27. Cai W, De La Fuente L, Arias CR (2013) Biofilm formation by the fish pathogen Flavobacterium columnare: development and parameters affecting surface attachment. Appl Environ Microbiol 79:5633-5642

28. De La Fuente L, Burr TJ, Hoch HC (2008) Autoaggregation of Xylella fastidiosa cells is influenced by type I and type IV pili. Appl Environ Microbiol 74:5579-5582

29. Olivares-Fuster O, Shoemaker CA, Klesius PH, Arias CR (2007) Molecular typing of isolates of the fish pathogen, Flavobacterium columnare, by singlestrand conformation polymorphism analysis. FEMS Microbiol Lett 269:63-69

30. Penttinen R, Kinnula H, Lipponen A, Bamford JKH, Sundberg L-R (2016) High nutrient concentration can induce virulence factor expression and cause higher virulence in an environmentally transmitted pathogen. Microb Eco 72:955-964

31. Penttinen R, Hoikkala V, Sundberg L-R (2018) Gliding motility and expression of motility-related genes in spreading and non-spreading colonies of Flavobacterium columnare. Front Microbiol 9:525

32. IDT PrimerQuest Tool. https://eu.idtdna.com/PrimerQuest/Home/Index. Accessed 7 Mar 2019

33. Kayansamruaj P, Dong HT, Hirono I, Kondo H, Senapin S, Rodkhum C (2017) Comparative genome analysis of fish pathogen Flavobacterium columnare reveals extensive sequence diversity within the species. Infect Genet Evol $54: 7-17$

34. Kumru S, Tekedar HC, Gulsoy N, Waldbieser GC, Lawrence ML, Karsi A (2017) Comparative analysis of the Flavobacterium columnare genomovar I and II genomes. Front Microbiol 8:1375

35. Donlan RM, Costerton JW (2002) Biofilms: survival mechanisms of clinically relevant microorganisms. Clin Microbiol Rev 15:167-193

36. Zhao R, Song Y, Dai Q, Kang Y, Pan J, Zhu L, Zhang L, Wang Y, Shen X (2017) A starvation-induced regulator, RovM, acts as a switch for planktonic/biofilm state transition in Yersinia pseudotuberculosis. Sci Rep 7:639

37. Kim J, Park HD, Chung S (2012) Microfluidic approaches to bacterial biofilm formation. Molecules 17:9818-9834

38. Lecuyer S, Rusconi R, Shen Y, Forsyth A, Vlamakis H, Kolter R, Stone HA (2011) Shear stress increases the residence time of adhesion of Pseudomonas aeruginosa. Biophys J 100:341-350

39. De La Fuente L, Montanes E, Wu M (2007) Assessing adhesion forces of type I and type IV pili of Xylella fastidiosa bacteria by use of a microfluidic flow chamber. Appl Environ Microbiol 73:2690-2696

40. Guardiola FA, Cuesta A, Esteban MÁ (2016) Using skin mucus to evaluate stress in gilthead seabream (Sparus aurata L.). Fish Shellfish Immunol 59:323-330

41. Bertotto D, Poltronieri C, Negrato E, Majolini D, Radaelli G, Simontacchi C (2010) Alternative matrices for cortisol measurement in fish. Aquac Res 41:1261-1267

42. Levipan HA, Avendaño-Herrera R (2017) Different phenotypes of mature biofilm in Flavobacterium psychrophilum share a potential for virulence that differs from planktonic state. Front Cell Infect Microbiol 7:76

43. McBride MJ, Nakane D (2015) Flavobacterium gliding motility and the type IX secretion system. Curr Opin Microbiol 28:72-77

44. Rhodes RG, Nelson SS, Pochiraju S, McBride MJ (2011) Flavobacterium johnsoniae sprB is part of an operon spanning the additional gliding motility genes sprC, sprD, and sprF. J Bacteriol 193:599-610 